\title{
TREND OF THE PSYCHOACTIVE POTENTIAL OF Cannabis sativa L. PLANT SAMPLES
}

\author{
Mirjana M. Dragoljić ${ }^{1 *}$, Branka B. Rodić-Grabovac ${ }^{2}$, Ljubica C. Vasiljević \\ Vesna Č. Matić1 ${ }^{1}$ Ljiljana O. Simurdić ${ }^{1}$ \\ ${ }^{1}$ Ministry of Internal Affairs of the Republic of Srpska, \\ Blvd. Desanke Maksimović 4, 78000 Banja Luka, Bosnia and Herzegovina \\ ${ }^{2}$ University of Banja Luka, Faculty of Technology, \\ Vojvode Stepe Stepanovića 23, 78000 Banja Luka, Bosnia and Herzegovina \\ ${ }^{3}$ University of East Sarajevo, Faculty of Technology, \\ Karakaj bb, 75400 Zvornik, Bosnia and Herzegovina \\ * Corresponding author; E-mail: mdragoljic@mup.vladars.net
}

(Received December 12, 2017; Accepted February 22, 2018)

\begin{abstract}
The products of the Cannabis sativa L. plant are the most widely used type of illegal drugs. In addition to growing under natural conditions, illegal breeders tend to produce, under artificial conditions, a plant with a high psychoactive potential i.e. high content of the psychoactive ingredient tetrahydrocannabinol. This paper includes the analyses results of the content of tetrahydrocannabinol in cannabis plant samples seized in the Republic of Srpska from 1999 to 2008 and from 2011 to 2016, in order to monitor the psychoactive potential of the samples available on the illegal market and the assessment trends in the future. The analyses of tetrahydrocannabinol content conducted for 3.718 samples was performed by gas chromatography with flame ionization detector according to the method of external standard. The results showed that the illegal market has samples of cannabis plant material with a noticeable difference in psychoactive ingredient content, with an increase in the number of high-potent samples. Besides the high-potent samples, health risks are caused by a great variety and sudden changes in potential of illegal drug samples, as it is necessary to continue to monitor the psychoactive potential of cannabis plants samples on the illegal market.
\end{abstract}

Keywords: Cannabis sativa L., psychoactive potential, tetrahydrocannabinol, gas chromatography.

\section{INTRODUCTION}

The products of the cannabis plant (lat. Cannabis sativa L.) are traditionally used as the most widespread illegal drug in the world. In the Republic of Srpska, cannabis plant material in different forms also comprises over $90 \%$ of confiscated drugs. This plant can be grown on every continent and almost in every country, whereas indoor growing, which has recently become more popular, also contributes to its expansion. In the last decades, there has been an increase of indoor growing of cannabis plant in many countries, which, apart from resulting in the greater yield, also has a significant effect on the chemical composition of the plant (TOONEN et al., 2006). The main psychoactive component of $C$. sativa is 7, 8, 9, 10tetrahydro-6, 6, 9-trimethyl-3-pentyl-6H-dibenzo (b, d) pyran-1-ol, also known in forensic literature as (-)-trans- $\Delta^{9}$ tetrahydrocannabinol, or simply tetrahydrocannabinol (THC) 
(BRENNEISEN, 2007). Various researches conducted in many countries have shown that the psychoactive potential (content of the psychoactive component THC) is on the rise in the cannabis plant, particularly in plants grown indoors, in artificial conditions. This form of growing is also present in this region (DRAGOLJIĆ and VASIĆ-DAKIĆ, 2013) but there has not been a comprehensive research into the tendencies and trends of the psychoactive potential of cannabis plant.

The psychoactive potential of illegal samples of cannabis products has been monitored in many countries for a long period of time, with the purpose of estimating its effect on people's health (CASCINI et al., 2012; ElSOHLY et al., 1984, 2000, 2016; KING et al., 2004; MEHMEDIĆ et al. 2010, POTTER et al. 2008). While consuming drugs, users adjust the dosage to the potency of the sample, which means that not only the highly potent samples are dangerous. The health risk also lies in sudden changes of potential of certain drugs present on the market or in great mutual differences in the psychoactive potential of illegal samples. Therefore, the aim of the research in this paper is monitoring the psychoactive potential of the samples available on the illegal market in Republic of Srpska and assessment trends in the future.

\section{MATERIALS AND METHODS}

Data on the concentrations of the psychoactive component tetrahydrocannabinol, processed in this paper, were obtained through the analysis of the samples of cannabis plant material in the chemical laboratory of the Forensic Unit, as a part of the Ministry of Interior of Republic of Srpska, in Banja Luka. The total of 3.718 plant samples, analyzed in the periods 1999-2008 and 2011-2016, were processed in this paper. Quantitative analysis of a sufficient number of samples was not carried out in 2009 and 2010, so those years did not cover by this study.

The analysis included the samples of Cannabis sativa L. in different forms: dried plant tops, dried and fragmented plant material (the form known as marijuana) in smaller or larger packages, improvised cigarettes ("joint") with a content of dried and fragmented plant material (the cannabis plant material alone or mixed with tobacco), fresh plant stems.

The samples were prepared appropriately, depending on their form (LABORATORY And Scientific Section of United Nations Office On Drugs And Crime, 2009). Dried plant material was used for analysis, from which seeds and bits of stem were removed. Where possible, the tops of the plant were selected as representative for analysis of the psychoactive ingredient tetrahydrocannabinol. Before the sample was taken, the fragmented plant material was homogenized. Fresh plants were dried at room temperature for 2 or 3 days, until the leaves became brittle. When taking samples for the analysis from improvised cigarettes the tobacco was removed, if it was present.

Chloroform (99-99.4\% purity) was used for the extraction of the sample. The extraction was carried out on a horizontal shaker Promax 1020, Heidolph (Schwabach, Germany) for 30 minutes, or in an ultrasonic bath Ultrasonic 475H, Langford Sonomatic (Bromsgrove, UK) for 15 minutes.

The reference standards of tetrahydrocannabinol (solutions in methanol, concentration $1 \mathrm{mg} / \mathrm{ml}$ ) used for the quantitative analysis were Alltech ${ }^{\circledR}$ - now Grace (Maryland, USA) and Lipomed $\mathrm{AG}^{\circledR}$ (Arlesheim, Switzerland).

The analyses were conducted using gas chromatograph with flame ionization detector. The instrument used from 1999 to 2008 was the model GC-17A, Shimadzu (Kyoto, Japan), and from 2011 to 2016 was the model GC Trace, Thermo Scientific (Waltham, USA).

The operating conditions for the instruments were: injector temperature: $280^{\circ} \mathrm{C}$, constant carrier gas flow $\left(\mathrm{N}_{2}\right): 2 \mathrm{ml} / \mathrm{min}$, temperature of the chromatographic oven: $260^{\circ} \mathrm{C}$ 
(isothermally). A volume of $1 \mu \mathrm{l}$ of sample extract was injected. During a long period of time, the capillary columns by different manufacturers were used for the process of separation of components. The following models of columns were used: HP-5 (Hewlett Packard - now Agilent, Santa Clara, USA), SPB-5 (Sigma-Aldrich - now Merck, Darmstadt, Germany) and Optima-5 (Macherey-Nagel, Düren, Germany). All those columns are with the same stationary phase: 5\% diphenyl and 95\% dimethylpolysiloxane. The elution order of basic cannabinoids with all above mentioned columns is as follows: cannabidiol, tetrahydrocannabinol and cannabinol.

The process of identification of the tetrahydrocannabinol in the samples was made based on the retention time (Rt) of tetrahydrocannabinol in referent standard solution, previously analized.

The quantitative analyses were conducted based on the external standard method, according to the formula:

$$
c_{x}=c_{R} \cdot \frac{A_{g}}{c_{g} \cdot A_{R}} \cdot 100[\%]
$$

where is:

$c_{\mathrm{x}}$ - concentration of the tetrahydrocannabinol in the sample [\%]

$c_{R}$ - concentration of the trahydrocannabinol in reference standard solution $[\mathrm{mg} / \mathrm{ml}]$,

$\mathrm{c}_{\mathrm{s}}$ - sample concentration $[\mathrm{mg} / \mathrm{ml}]$,

$A_{s}$ - area of tetrahydrocannabinol in the chromatogram of the sample,

$A_{R}$ - area of tetrahydrocannabinol in the chromatogram of trahydrocannabinol reference standard solution.

\section{RESULTS AND DISCUSSION}

The quantitative analysis of the content of tetrahydrocannabinol in the samples of plant material involved the so-called total THC including tetrahydrocannabinol acid (THCA), which decarboxylates at high temperature to tetrahydrocannabinol. During the gas chromatographic analysis, the decarboxylation process takes place in the injector (LABOratory And ScIENTIFIC Section of United Nations OfFice On Drugs ANd CRime, 2009; Thomas and ElSohly, 2016). The analysis of the total THC (THC + THCA) is very common in forensics, because it is evident that even during consummation (most commonly through smoking) decarboxylation of THCA occurs under the influence of high temperature, so the total THC represents a real potential of the samples aimed for abuse (RYMANOVSKI, 2014). The content of THC in the samples was expressed as percentage of THC in dry plant material, which is also considered as a common method in forensics.

The results of the analysis shown that the content of the psychoactive component tetrahydrocannabinol in the cannabis plant samples confiscated in the Republic of Srpska range from $0.01 \%$ to $27.48 \%$. This indicates the presence of cannabis plant samples with great variations of the psychoactive potential on the illegal market.

Based on the results of the analyses, the samples were classified into six groups depending on the content of THC:

- group I - THC $\leq 0.2 \%$ (not considered as drugs),

- group II - THC is $0.2-0.5 \%$ (effects of consummation are minimal),

- group III - THC is $0.5-2 \%$ (low-potency samples),

- group IV - THC is $2-5 \%$ (medium-potency samples), 
- group V - THC is 5-10\% (medium-to-high-potency samples) and

- group VI - THC > 10\% (high-potency samples).

Tables 1 and 2 show a share for each group of samples according to the content of THC.

Table 1. Percentage share of individual groups of samples according to the content of THC for the period 1999-2008.

\begin{tabular}{lcccccc}
\hline \multirow{2}{*}{ Year } & \multicolumn{6}{c}{ Percentage of particular groups according to the THC content } \\
\cline { 2 - 7 } & $\begin{array}{c}\text { I } \\
(\leq \mathbf{0 . 2} \%)\end{array}$ & $\begin{array}{c}\text { II } \\
(\mathbf{0 . 2 - 0 . 5 \%})\end{array}$ & $\begin{array}{c}\text { III } \\
(\mathbf{0 . 5 - 2} \%)\end{array}$ & $\begin{array}{c}\mathbf{I V} \\
(\mathbf{2 - 5} \%)\end{array}$ & $\begin{array}{c}\mathbf{V} \\
\mathbf{( 5 - 1 0 \% )}\end{array}$ & $\begin{array}{c}\text { VI } \\
(>\mathbf{1 0} \%)\end{array}$ \\
\hline $\mathbf{1 9 9 9}$ & 5.22 & 11.30 & 42.61 & 28.70 & 12.18 & - \\
$\mathbf{2 0 0 0}$ & 5.23 & 8.50 & 30.72 & 36.60 & 15.68 & 3.27 \\
$\mathbf{2 0 0 1}$ & 5.24 & 1.57 & 19.90 & 48.69 & 19.37 & 5.24 \\
$\mathbf{2 0 0 2}$ & 0.98 & 3.90 & 25.36 & 37.07 & 21.95 & 10.73 \\
$\mathbf{2 0 0 3}$ & 1.42 & 5.21 & 21.33 & 42.18 & 22.75 & 7.11 \\
$\mathbf{2 0 0 4}$ & 5.00 & 7.14 & 53.57 & 24.29 & 7.14 & 2.86 \\
$\mathbf{2 0 0 5}$ & 4.65 & 8.72 & 32.56 & 29.07 & 15.70 & 9.30 \\
$\mathbf{2 0 0 6}$ & 1.96 & 5.88 & 35.30 & 41.67 & 13.72 & 1.47 \\
$\mathbf{2 0 0 7}$ & 3.20 & 10.05 & 30.13 & 33.79 & 17.35 & 5.48 \\
$\mathbf{2 0 0 8}$ & 3.43 & 6.29 & 25.15 & 29.71 & 25.72 & 9.71 \\
\hline
\end{tabular}

Table 2. Percentage share of individual groups of samples according to the content of THC for the period 2011-2016.

\begin{tabular}{|c|c|c|c|c|c|c|}
\hline \multirow{3}{*}{ Year } & \multicolumn{6}{|c|}{ Percentage of particular groups according to the THC content } \\
\hline & I & II & III & IV & $\mathbf{V}$ & VI \\
\hline & $(\leq 0.2 \%)$ & $(0.2-05 \%)$ & $(0.5-2 \%)$ & $(2-5 \%)$ & $(5-10 \%)$ & $(>10 \%)$ \\
\hline 2011 & 9.87 & 7.89 & 33.55 & 33.55 & 13.82 & 1.32 \\
\hline 2012 & 2.89 & 7.85 & 26.03 & 42.56 & 18.60 & 2.07 \\
\hline 2013 & 1.50 & 4.50 & 17.42 & 26.73 & 30.93 & 18.92 \\
\hline 2014 & 2.60 & 5.41 & 18.18 & 37.01 & 31.60 & 5.19 \\
\hline 2015 & 4.11 & 5.57 & 25.81 & 25.81 & 27.86 & 10.85 \\
\hline 2016 & 2.04 & 6.12 & 19.90 & 31.12 & 29.34 & 11.48 \\
\hline
\end{tabular}

The average amount of the samples with the content of $\mathrm{THC}>0.2 \%$ (the so-called drug-type samples) is $96.18 \%$, ranges from $90.13 \%$ (2011) to $99.02 \%$ (2002). The most common are the samples belonging to group IV (2-5\% of THC) and III (0.5-2\% of THC) which together make more than $60 \%$ of the total number of samples.

The percentage share of samples with a lower content of THC (groups I, II and III) shows a tendency of decrease during the years, whereas that of the groups with a high THC content (groups V and VI), apart from occasional deviation in certain years, shows a tendency of increase. Thus, up to the year 2012, the most common samples were those of groups III and IV, whereas after 2012, there was a significant rise in the percentage share of the group V samples. In 2013, it represented $30.93 \%$ of the total number of samples, which is a significant increase compared to the $7.14-25.72 \%$ in the earlier period. In the same year, maximum share of highly potent samples (group VI) was recorded. 
The decrease of the number of low-potency samples and the increase of the number of high-potency samples correlates with the average annual potential (the average value of THC content in the samples), shown in diagram (Fig. 1). This was particularly evident in the following years: 2002, 2003, 2008, and from 2013 to 2016, in which the average annual potentials have high values.

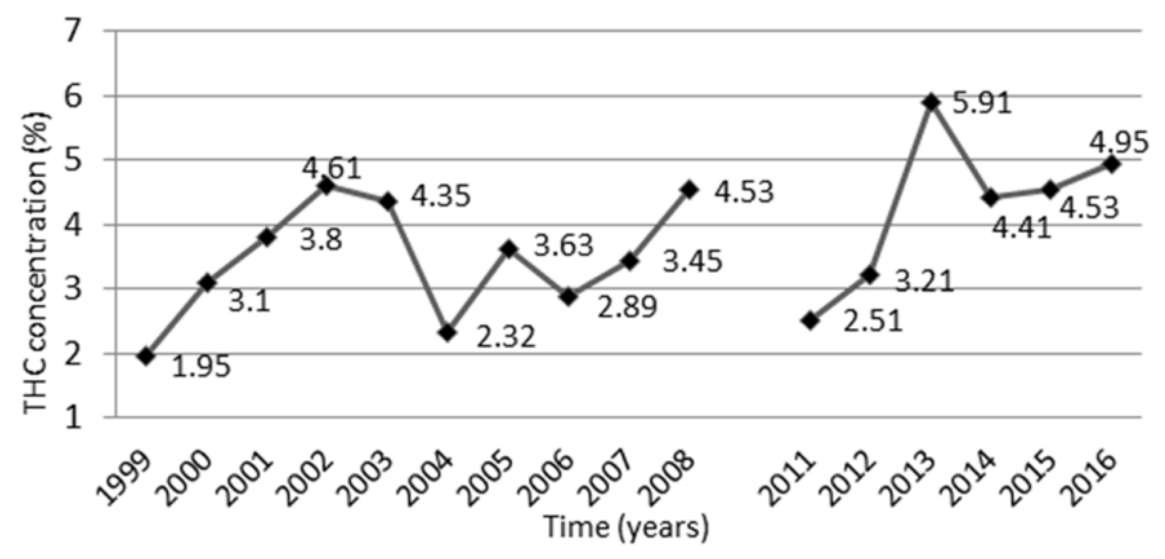

Figure 1. Diagram representing potential of cannabis plant samples for the period 1999-2008 and 2011-2016.

Table 3 shows the average annual potential as well as corresponding values of standard deviation, and minimum and maximum values of THC content. Based on the average annual psychoactive potential of the analyzed samples, shown in the diagram (Fig. 1) and Table 3, it becomes evident that, apart from occasional decrease (years 2004, 2006, 2011), the average annual psychoactive potentials are generally increasing. An occasional drop in the potential could be associated with police operations aimed at discovering and bringing organized criminal groups to justice, which resulted in a lower total supply of drugs on the illegal market at least temporarily (GOVERNMENT OF REPUBLIC OF SRPSKA, 2016).

Table 3. Average annual potential (average content of THC), standard deviation, lowest and highest THC content.

\begin{tabular}{ccccc}
\hline Year & $\begin{array}{c}\text { Mean of THC } \\
{[\%]}\end{array}$ & $\begin{array}{c}\text { SD } \\
{[\mathbf{\Psi}]}\end{array}$ & $\begin{array}{c}\text { Min. THC } \\
{[\%]}\end{array}$ & $\begin{array}{c}\text { Max. THC } \\
{[\%]}\end{array}$ \\
\hline $\mathbf{1 9 9 9}$ & 1.95 & 1.81 & 0.02 & 8.61 \\
$\mathbf{2 0 0 0}$ & 3.10 & 2.81 & 0.06 & 14.01 \\
$\mathbf{2 0 0 1}$ & 3.80 & 2.74 & $<0.01$ & 17.08 \\
$\mathbf{2 0 0 2}$ & 4.61 & 3.92 & 0.02 & 22.58 \\
$\mathbf{2 0 0 3}$ & 4.35 & 3.53 & 0.02 & 22.63 \\
$\mathbf{2 0 0 4}$ & 2.32 & 2.71 & 0.01 & 22.59 \\
$\mathbf{2 0 0 5}$ & 3.63 & 3.69 & 0.01 & 22.45 \\
$\mathbf{2 0 0 6}$ & 2.89 & 2.13 & 0.04 & 11.88 \\
$\mathbf{2 0 0 7}$ & 3.45 & 3.14 & 0.03 & 17.30 \\
$\mathbf{2 0 0 8}$ & 4.53 & 3.97 & 0.08 & 27.48 \\
$\mathbf{2 0 1 1}$ & 2.51 & 2.26 & 0.02 & 11.00 \\
$\mathbf{2 0 1 2}$ & 3.21 & 2.37 & 0.06 & 12.12 \\
$\mathbf{2 0 1 3}$ & 5.91 & 4.21 & 0.10 & 25.80 \\
$\mathbf{2 0 1 4}$ & 4.41 & 3.07 & 0.04 & 20.80 \\
$\mathbf{2 0 1 5}$ & 4.53 & 3.79 & 0.02 & 18.30 \\
$\mathbf{2 0 1 6}$ & 4.95 & 3.89 & 0.04 & 22.91 \\
\hline
\end{tabular}


There are similarities in the tendencies when compared to the available data from certain other countries - similar increase in the potential of cannabis was recorded in Europe, USA and Australia (NIESNIK et al., 2015; TsUMURA et al. 2012); UNITED NATIONS OfFICE ON Drugs AND CRIME, 2011, 2014, 2015). According to a report of the EUROPEAN MONITORING Centre For Drugs And Drug AdDiction and Europol (2016), the potential of cannabis products has doubled in the last decade. Based on the available statistical data of the European Monitoring CENTRE For Drugs And Drug AdDiction (2017), given in Table 4, it can be concluded that in the monitoring period (especially since 2003), cannabis plant potential in certain European countries (Bulgaria, Czech Republic, Estonia, Hungary, Poland and Portugal, for example) has increased significantly, and in Austria it has almost doubled.

The psychoactive potential increased greatly in France, until 2002, and after that there was a period of relative stability. From 2005 to 2010, there some fluctuations were noticed, and in 2011 again there was a considerable increase. In Italy, the potential was relatively stable up to 2012, when a significant rise was recorded. Belgium, Germany and Luxemburg, are countries with a relatively stable, but traditionally high, cannabis potential. According to the data available from the EMCDDA, in Germany it ranged from 8-10, and in Luxemburg from 8-12 in the period 2002-2014 (http://www.emcdda.europa.en/data/stats, accessed 08 June 2017).

Table 4. Average annual potential of cannabis plant material in some European countries.

\begin{tabular}{|c|c|c|c|c|c|c|c|c|c|c|}
\hline \multirow[b]{2}{*}{ 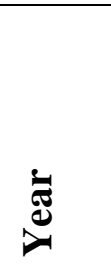 } & \multicolumn{10}{|c|}{ Mean potency of herbal cannabis (\% THC) } \\
\hline & 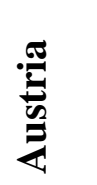 & $\underset{D}{D}$ & 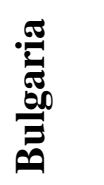 & ల్ల & 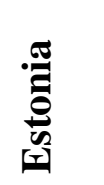 & 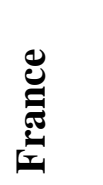 & $\underset{\Xi}{\stackrel{\Xi}{\Xi}}$ & 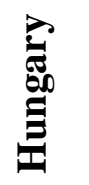 & 冚 & 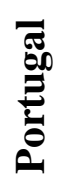 \\
\hline 2000 & - & 10.4 & - & - & - & $<2.0$ & 6.3 & - & - & 0.2 \\
\hline 2001 & 5.0 & 6.0 & - & - & - & $<2.0$ & 5.8 & 1.0 & - & 5.2 \\
\hline 2002 & 9.0 & 6.0 & - & - & - & 8.0 & 4.9 & 0.5 & - & 3.1 \\
\hline 2003 & - & 13.8 & 2.0 & 9.2 & - & 8.5 & 7.9 & 1.2 & - & 1.4 \\
\hline 2004 & 4.8 & 13.3 & - & 3.0 & - & 8.0 & 5.8 & 1.7 & 0.6 & 3.5 \\
\hline 2005 & 5.6 & - & 2.4 & 3.8 & 3.3 & 6.1 & - & 1.7 & 1.0 & 3.0 \\
\hline 2006 & 7.2 & 6.7 & 2.0 & 4.5 & 2.0 & 7.8 & 5.4 & 1.8 & 1.3 & 6.3 \\
\hline 2007 & 6.7 & 9.2 & 1.5 & 4.7 & - & 7.5 & 2.2 & 1.2 & 5.2 & 3.9 \\
\hline 2008 & 7.2 & 9.1 & 1.6 & 5.5 & 6.6 & 5.8 & 4.7 & 1.4 & 6.9 & 4.8 \\
\hline 2009 & 5.9 & 9.9 & 2.4 & 4.2 & 8.0 & 8.5 & 5.9 & 1.3 & 7.7 & 3.8 \\
\hline 2010 & 7.5 & 11.1 & 7.5 & 7.7 & 10.0 & 9.8 & 7.8 & 1.3 & 7.6 & 5.2 \\
\hline 2011 & 7.0 & 10.7 & 3.7 & 7.2 & 11.1 & 10.6 & 6.4 & 1.0 & 9.6 & 5.2 \\
\hline 2012 & 9.7 & 13.2 & 3.5 & 7.1 & 13.4 & 10.0 & 8.5 & 5.0 & 8.7 & 5.4 \\
\hline 2013 & 9.6 & 10.4 & 9.1 & 10.0 & 13.4 & 12.7 & 12.4 & 6.5 & 9.8 & 6.6 \\
\hline 2014 & 8.9 & 13.0 & 13.1 & 8.2 & 12.7 & 13.0 & 10.5 & 7.2 & 11.0 & 7.8 \\
\hline 2015 & 9.8 & 21.7 & 12.3 & 8.3 & 13.5 & 11.4 & 8.9 & 6.8 & 10.0 & 8.3 \\
\hline
\end{tabular}

The psychoactive potential of the cannabis plant in the Republic of Srpska is not as high as in some European countries (Belgium, Germany, Luxemburg, France, Italy, etc.), but it is evidently rising, and so is the number of high-potency cannabis plant samples. Such trends can be expected to continue in the future.

Although comparison of results among different countries, over a long period of time, depends on many factors (the type of cannabis product, method of sampling, natural 
degradation of THC with time, use of different techniques for analysis, etc.), the data given are indicative of both present changes in the psychoactive potential and future trends as well (TURNer and ElSOHLy, 1979; Ross and ElSOHLy, 1997; Dragoljí et al., 2013). In order to obtain reliable results that can be mutually compared, international organizations specializing in the problem of illegal drugs, such as UNDOC, ENFSI and SWGDRUG, recommend standardized sampling and analyses procedures and organize interlaboratory testing (SCIENTIFIC Working Group For The ANAlysis Of SEIZED Drugs, 2003, 2005, 2016; European Network Of Forensic Science Institutes and United Nations OfFice ON DRUG AND CRIME, 2009).

The psychoactive potential and pharmacological action of cannabis are complex issues depending on multiple factors. $C$. sativa $\mathrm{L}$. contains over one hundred cannabinoids, whose effects are not entirely known (RADWAN et al., 2015). However, it is estimated that cannabidiol (CBD) reduces psychoactive effects of tetrahydrocannabinol (THC) (UNITED NATIONS OfFICE ON DRUGS AND CRIME, 2015), the reason why a more detailed description of pharmacological effects of cannabis products should also consider the content of CBD. The content of $\mathrm{CBD}$ is not frequently monitored, which results in some difficulties in the estimation of the effects of cannabis on health.

Results analyzed for the purpose of this paper revealed an increasing presence of the samples with a higher content of THC and a lower content of CBD, unlike before, when the content of CBD was present in significant quantities.

It is clear that the potential of cannabis plant should be further monitored, because international organizations specializing in these problems report increasing cases of the users of cannabis who need medical treatment (UNITED NATIONS OfFICE ON DRUGS AND CRIME, 2015). Considering the fact that a potent plant will give a potent product (cannabis resin, known as hashish, and cannabis oil, which, depending on the manufacturing procedure, can contain up to $90 \%$ of THC), the health risks for users can be rather serious. This problem should be dealt with much more attention, because, apart from illegal consummation, cannabis oil is becoming a common adjuvant therapy in the treatment of certain diseases.

\section{CONCLUSION}

More than $90 \%$ of confiscated samples of C. sativa L. plant material in the Republic of Srpska are samples whose content of the psychoactive component tetrahydrocannabinol is in excess of $0.2 \%$, the so-called drug-type samples.

The illegal market of the Republic of Srpska is characterized by the presence of cannabis samples with varying content of the psychoactive component, the so-called lowpotency samples, medium-potency, and the high-potency samples. The number of highpotency samples of cannabis plant is increasing, and so is the average annual potential. The lowest average annual psychoactive potential in the period observed, expressed as the percentage of THC, was $1.95 \%$ (in 1999), and the highest was $5.91 \%$ (2013). There is also evidence of the increasing number of the samples with a high content of tetrahydrocannabinol and a low content of cannabidiol, unlike the situation before, when the samples also contained significant amounts of cannabidiol.

The results obtained suggest the importance of further monitoring of the psychoactive potential of the samples of illegal drugs available on the market, because in addition to highpotency, the health risk lies in great potential differences among the samples, as well as sudden changes of psychoactive potential of illegal drugs. 


\section{References:}

[1] BRenneisen, R. (2007): Chemistry and Analysis of Phytocannabinoids and Other Cannabis Constituents. Chapter 2. In: ElSohly, M.A. (ed.). Marijuana and the cannabinoids. Humana Press, New Jersey: 17-49 pp.

[2] Cascini, F., Aiello, C., DiTanna, G. (2012): Increasing Delta-9-Tetrahydrocannabinol $(\triangle 9-T H C)$ Content in Herbal Cannabis Over Time: Systematic Review and MetaAnalysis. Current Drug Abuse Reviews. 5 (1): 32-40.

[3] Dragoljić, M., VASIĆ-DaKić, B. (2013): Features of investigation of illegal laboratories for the production of marijuana - scientific approach. VI International scientific conference "Contemporary materials 2013", Banja Luka, Proceeding: 397406. [in Serbian with English summary]

[4] Dragoljić, M., ŠKundrić, B., ŠKundrić-Penavin, J., Matić, V. (2013): Kinetics of the reaction of tetrahydrocannabinol disintegration in samples of marijuana. III International congres "Engineering, environment and materials in processing industry" Jahorina 2013, Proceeding: 708-718. [in Serbian with English summary]

[5] ElSohly, M.A., Holley, J.H., Lewis, G.S., Russell, M.H., Turner, C.E. (1984): Constituents of Cannabis sativa L. XXIV: The Potency of Confiscated Marijuana, Hashish, and Hash Oil Over a Ten-Year Period. J. Forensic Sci. 29 (2): 500-514.

[6] ElSohly, M.A., Ross, S.A., Mehmedić, Z., Arafat, R., BaO, Y., Banahan, B.F. (2000): Potency Trends of D9-THC and Other Cannabinoids in Confiscated Marijuana from 1980-1997. J. Forensic Sci. 45 (1): 24-30.

[7] ElSohly, M.A., Mehmedić, Z., Foster, S., Gon, C., Church, J.C. (2016): Changes in Cannabis Potency over the Last Two Decades (1995-2014) - Analysis of Current Data in the United States. Biological Psychiatry 79 (7): 613-619.

doi: 10.1016/j.biopsych.2016.01.004

[8] European Monitoring Centre For Drugs And Drug Addiction (EMCDDA) And EUROPOL (2016): EU Drug Markets Report: In-Depth Analysis. Publications Office of the European Union, Luxemburg: 55-71 pp.

[9] EuRopean NeTwORK Of ForensiC SCIENCE INSTITUTES (ENFSI) in cooperation with the United Nations OfFice ON Drug AND CRIME (UNODC) (2009): Guidelines on Representative Drug Sampling. United nations, New York.

[10] Government Of Republic Of SRPSKa (2016): Strategy for control and combat of abuse drugs in the Republic of Srpska in the period 2016-2021. [in Serbian]: 9-10 pp.

[11] King, L.A., CARPENTIER, C., GRIFFITHS, P. (2004): An overview of cannabis potency in Europe. European Monitoring Centre for Drugs and Drug Addiction (EMCDDA), Luxembourg: 29-41 pp.

[12] Laboratory And Scientific Section of United Nations OfFice On Drugs And CRIME (2009): Recommended Methods for the Identification and Analysis Cannabis and Cannabis Products. United Nations, New York: 25-40 pp.

[13] Mehmedić, Z., Chandra, S., Slade, D., Denham, H., Foster, S., Patel, A.S., Ross, S.A., Khan, I.A., ElSohly, M.A. (2010): Potency Trends of $\Delta 9$-THC and Other 
Cannabinoids in Confiscated Cannabis Preparations from 1993 to 2008. J. Forensic Sci. 55 (5): 1209-1217. doi: 10.1111/j.1556-4029.2010.01441.x

[14] Niesnik, R.J.M., Righter, S., Koeter, M.W., Brunt, T.M. (2015): Potency Trends of $\triangle 9$-THC, cannabidiol and cannabinol in cannabis in the Netherlands: 2005-2015. Addiction 110 (12): 1941-1950. doi: 10.1111/add.13082

[15] Potter, D.J., Clark, P., Brown, M.B. (2008): Potency of $\Delta 9$-THC and Other Cannabinoids in Cannabis in England in 2005. J. Forensic Sci. 53 (1): 90-94. doi: 10.1111/j.1556-4029.2007.00603.x

[16] Radwan, M.M., ElSohly, M.A., El-Alfy, A.T., Ahmed, S.A., Slade, D., Husni, A.S., Manly, S.P., Wilson, L., Seale, S., Cutler, S.J., Ross, S.A. (2015): Isolation and Pharmacological Evaluation of Minor Cannabinoids from High-Potency Cannabis sativa. J Nat Prod 78 (6): 1271-1276. doi: 10.1021/acs.jnatprod.5b00065

[17] RyMAnovski, M. (2014): Cannabis - review of the issues related to determination of the total content of delta-9-tetrahydrocannabinol ( $\Delta-9-\mathrm{THC})$ and delta-9tetrahydrocannabinolic acid ( $\Delta-9$-THCA). Problemy Kryminalistyki. 285 (3): 1-18.

[18] Ross, S.A., ElSohly, M.A. (1997): CBN and $\triangle 9$-THC concentration ratio as an indicator of the age of stored marijuana samples. Bulletin on Narcotics XLIX and L: 139-147.

[19] Scientific Working Group For The Analysis Of Seized Drugs (SWGDRUG) (2016): Recommendations, Version 7.1.

[20] Scientific Working Group For The Analysis Of SeIzed Drugs (SWGDRUG) (2003): Methods of Analysis - Drug Identification.

[21] ScIEntific Working Group For The Analysis Of SeIZEd Drugs (SWGDRUG) (2005): Marijuana.

[22] Thomas, B.F., ElSohly, M.A. (2016): The Analytical Chemistry of Cannabis. Elsevier, Amsterdam: 67 pp.

[23] ToOnen, M., Ribot, S., Thissen, J. (2006): Yield of illicit indoor cannabis cultivation in the Netherlands. J. Forensic Sci. 51 (5): 1050-1054. doi: 10.1111/J.15564029.2006.00228.X

[24] Tsumura, Y., Aoki, R., Tokieda, Y., Akutsu, M., Kawase, Y., Kataoka, T., TAKagi, T., Mizuno, T., Fukada, M., Fuji, H., Kurahashi, K. (2012): A survey of the potency of Japanese illicit cannabis in fiscal year 2010. Forensic Science International 221 (1-3): 77-83. doi: 10.1016/j.forsciint.2012.04.005

[25] Turner, C.E., ElSohly, M.A. (1979): Constituents of Cannabis sativa L.: XVI. A possible decomposition pathway of $\Delta 9$-tetrahydrocannabinol to cannabinol. $J$ Heterocyclic Chem. 37: 1667-1668. doi: 10.1002/jhet.5570160834

[26] United Nations Office On Drugs And CRime (2011): World Drug Report 2011. United Nations, New York: 175-206 pp.

[27] United Nations OfFice On Drugs And CRime (2015): World Drug Report 2015. United Nations, New York: 57-66 pp.

[28] United Nations OfFice On Drugs And CRIME (2014): The Illicit Drug Trade Through South Eastern Europe. United Nations: 98-107 pp.

[29] http://www.emcdda.europa.en/data/stats Accessed 08 June 2017. 